\title{
Antisense and yet sensitive: Copy number control of rolling circle- replicating plasmids by small RNAs ${ }^{\S}$
}

Advanced Review

\section{Radoslaw Pluta ${ }^{1}$ and Manuel Espinosa ${ }^{2^{*}}$}

${ }^{1}$ International Institute of Molecular and Cell Biology in Warsaw, 02-109, Warsaw, Poland, and ${ }^{2}$ Centro de Investigaciones Biológicas, Consejo Superior de Investigaciones Científicas, Ramiro de Maeztu, 9, 28040 Madrid, Spain

Emails: $\underline{\text { radplu@gmail.com; mespinosa@cib.csic.es }}$

Conflict of interest: The authors have declared no conflicts of interest for this article

${ }^{\S}$ Dedicated to Prof. Ramón Díaz-Orejas on occasion of his retirement 


\begin{abstract}
Bacterial plasmids constitute a wealth of shared DNA amounting to about $20 \%$ of the total prokaryotic pangenome. Plasmids replicate autonomously and control their replication by maintaining a fairly constant number of copies within a given host. Plasmids should acquire a good fitness to their hosts so that they do not constitute a genetic load. Here we review some basic concepts in Plasmid Biology, pertaining to the control of replication and distribution of plasmid copies among daughter cells. A particular class of plasmids is constituted by those that replicate by the rolling circle mode (RCR-plasmids). They are small double-stranded DNA molecules, with a rather high number of copies in the original host. RCR-plasmids control their replication by means of a small short-lived antisense RNA, alone or in combination with a plasmidencoded transcriptional repressor protein. Two plasmid prototypes have been studied in depth, namely the staphylococcal plasmid pT181 and the streptococcal plasmid pMV158, each corresponding to the two types of replication control circuits, respectively. We further discuss possible applications of the plasmid-encoded antisense RNAs and address some future directions that, in our opinion, should be pursued in the study of these small molecules.
\end{abstract}

(191 words)

Key words: Bacterial plasmids / Copy number / Control of replication / Countertranscribed RNA / Hairpins / Kissing complex / Rolling-circle replication / Transcriptional repression 


\section{INTRODUCTION}

Flourishing of the RNA world could not have been possible without the pioneer work radiated from the Tomizawa laboratory more than 30 years ago, when they published the first reports on antisense RNAs (asRNA) and their role in the control of replication of plasmid ColE1 ${ }^{1,2}$. These findings opened the ways to the discovery and use of small non-coding asRNAs, to the strategy of RNA interference in gene therapy ${ }^{3}$, and to the development of transcription-activating small RNAs ${ }^{4}$. Nowadays, to achieve a proper perspective of the field, it is important to review basic concepts on replication of bacterial plasmids, its control, and their influence on the bacterium/plasmid lifestyles. By doing so, we can obtain a broad view of a field that guided the research on small RNAs for a number of years, and that is still useful in constructing tools for System Biology-based elements to control gene expression by RNAs ${ }^{5}$. Bacterial plasmids could be considered as selfish DNA molecules that, in some cases, have become beneficial or symbionts to the hosts ${ }^{6}$. Plasmids have a size that varies from $\sim 1$ to several hundreds of kilobase pairs $(\mathrm{kb})$. In the first case, the plasmid will carry only the functions involved in replication and its control ${ }^{7,8}$, whereas large plasmids incorporate into their backbones one or several operons that may be involved in degradative pathways of xenobiotic compounds ${ }^{9}$, symbiosis for nitrogen fixation by plants, as in the rhizobia family of bacteria ${ }^{10}$, antibiotic-resistance traits ${ }^{11}$, etc. Plasmids replicate in autonomous and controlled manner, although they use different mechanisms to do so ${ }^{12}$. We will review examples of replication control circuits in small plasmids replicating by the asymmetric rolling circle mechanism, termed RCRplasmids. Whereas these plasmids have in common their replicative mechanisms, they control their replication by, at least, two ways: i) a single antisense (as)RNA, and ii) a combination of an asRNA and a transcriptional repressor protein ${ }^{13}$. These regulatory processes are, by no means, exclusive of RCR-plasmids, since they are shared with plasmids replicating by the theta and by the strand-displacement modes 12-14. Further, involvement of a transcriptional repressor protein in conjunction with an asRNA, has been reported for the theta-replicating plasmid R1 ${ }^{15,16}$, and has been reviewed in depth ${ }^{17}$. The examples of these copy number control mechanisms present in theta-replicating plasmids will not be addressed here, and will be suggested as further readings.

Bacterial plasmids are supercoiled DNA molecules that replicate autonomously and in a controlled manner. Plasmid replication is random and independent of the replication of the host chromosome, although plasmids use the host replication machinery thoroughly, especially RNA- (RNAP) and DNA- (DNAP) polymerases, single-stranded DNA binding protein (SSB), and DNA gyrase. To control their replication, plasmids encode negatively-acting elements that: i) limit their replication frequency to one round per copy and per cell cycle ${ }^{18}$, and ii) correct the fluctuations in their copy numbers that occur along the host cell cycle ${ }^{19-22}$. Replication control is exerted at the initiation stage ${ }^{23}$, and not at later events (elongation or termination) to avoid useless energy expenses and, in the case of plasmids, to control their replication by elements encoded by the replicon and not by delegation of functions to the host (always a risky matter). Because of their extrachromosomal location, their use of the host replicative machinery, and their number of copies (from one to several dozens), plasmids may constitute a genetic cargo to the host that carries them, although selective advantages may eventually exist. Depending on the plasmid, the host, and environmental conditions, harbouring 
a plasmid may impose a metabolic burden to the cell carrying them. This would result in an increase in the doubling time of the plasmid-carrying cells compared to the plasmid-free ones. As a consequence, in mixed populations of plasmid-free and plasmid-carrying cells, the former population would overgrow the latter, and the plasmid would be eliminated from the population ${ }^{24,25}$. It follows that the genetic load imposed by the plasmid must be compensated by an increase in the fitness of the plasmid to the host. Then, this genetic burden can be considered negligible ${ }^{26}$. An improper fitness will result in plasmid segregational instability and, ultimately, in plasmid loss ${ }^{27-29}$.

\section{RCR-PLASMIDS}

The RCR-plasmid family is very abundant (hundreds of them sequenced so far); many of them carry a mobilization module, so they can be horizontally transferred among several hosts by the functions provided by bigger, 'auxiliary' plasmids ${ }^{30}$. Thus, these RCR-plasmids constitute a large pool of DNA that is shared among bacteria ${ }^{31}$. RCR-plasmids have a small size that, in general, varies from $\sim 1$ to less than $10 \mathrm{~kb}$, although plasmids of $\sim 30 \mathrm{~kb}$ have been reported ${ }^{32}$. This limitation of maximum size is related to their mode of replication because it generates single-stranded DNA intermediates (Figure 1) that are recombinogenic and deleterious for the harbouring cells ${ }^{33-35}$. RCR-plasmids are constructed by combination of different gene cassettes, so that they usually harbour up to three main modules involved in: i) replication of the leading strand and copy number control; this is the only essential module and it is the one that constitutes the plasmid signature and defines the RCR-plasmid families; ii) antibiotic-resistance determinant, and iii) mobilization, since many of them are mobilized by functions provided by auxiliary replicons ${ }^{12,30,36}$. Further, some open reading frames related to metabolic or to unknown functions ('cryptic' plasmids) have been reported ${ }^{37}$. The initiator of replication protein (generically termed Rep) and the relaxase that initiates mobilization (Mob) have both DNA nicking and closing activities on supercoiled DNA, and they both induce hairpin extrusion at their cognate origins of replication (dso) and of transfer (oriT) ${ }^{38,39}$. Nicking of a supercoiled molecule by the cognate Rep protein would result in relaxed plasmid forms that would be unproductive for transfer, and vice versa ${ }^{35,36}$. In addition, RCR-plasmids contain one or two origins of lagging-strand replication, termed sso; they are specific noncoding regions that have the potential to generate imperfect hairpin structures on singlestranded (ss) DNA. The sso regions are functional in an orientation-dependent manner ${ }^{40}$ and require unpaired sequences within this region ${ }^{36,41,42}$. Based on the replication and control module, RCR-plasmids have been grouped into three main families: i) Rep_trans, represented by plasmids pT181 and pC221; ii) Rep_1, represented by plasmids pUB110 and pC194, and iii) Rep_2, the representative being plasmids pMV158 and pE194 ${ }^{43}$. Plasmids belonging to the different families seem to control their replication by different mechanisms (see below). 


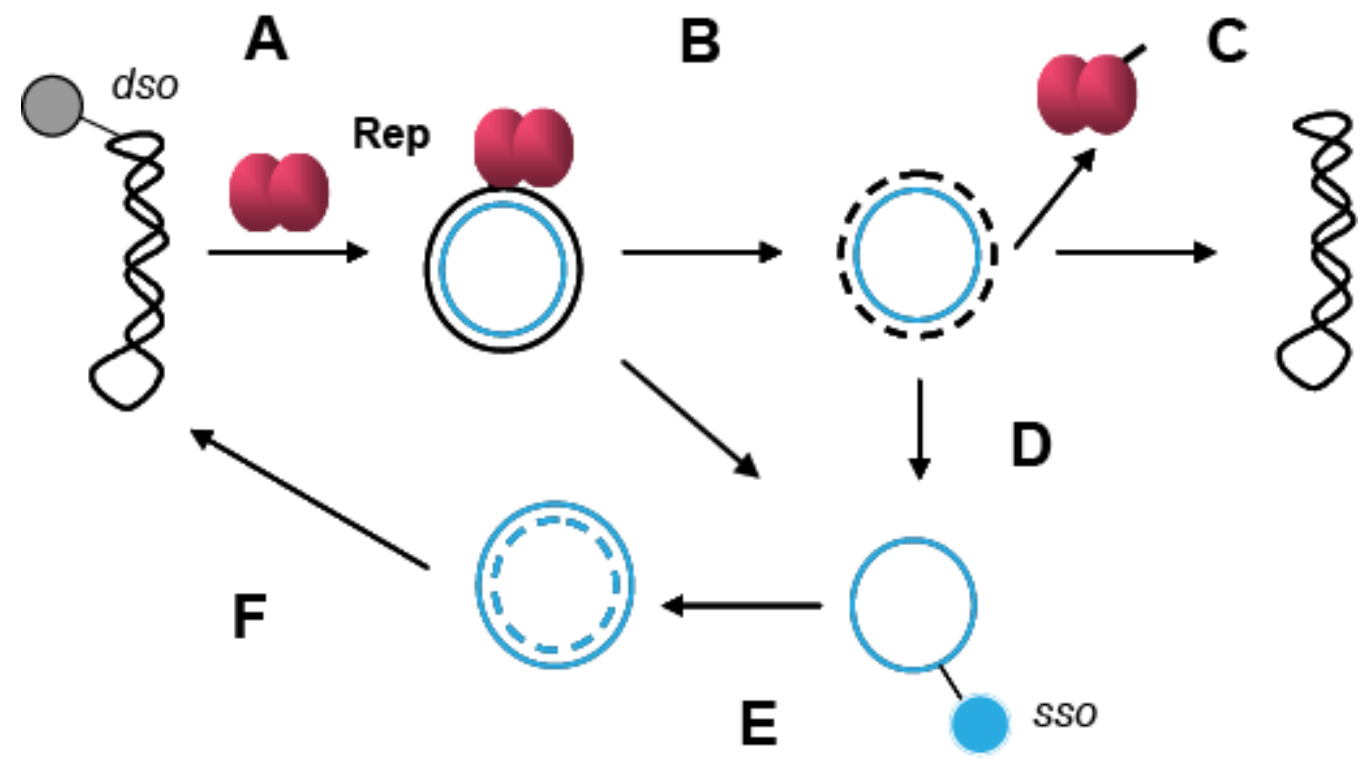

FIGURE 1 Simplified model of plasmid replication by the rolling circle mechanism. The initiator of replication (Rep) dimeric protein (red ellipses) recognizes, binds to it, and cleaves the phosphodiester bond of a specific di-nucleotide (within a stem-loop structure, represented by a grey circle) at the origin of replication of the leading strand (dso) on supercoiled DNA. This reaction leaves a 3'-OH end that will be used as primer to assemble the replisome. The various stages of the process (A-F) are detailed in the text. The single-stranded origin of replication, sso (filled circle in blue), is generated in the ssDNA intermediate by intrastrand pairing. More detailed representations of the mechanism of replication by the RC-mode have been published ${ }^{35,36,44,45}$.

Being small, RCR-plasmids respond to the philosophy of 'travel light', that is: i) to encode only the essential genes required for their vertical propagation and, in several instances, horizontal transfer, and ii) to use host proteins that are abundant and present in all hosts, like DNAP, RNAP, SSB, DNA gyrase, and DNA helicase ${ }^{46}$, 47; this latter feature is not exclusive of RCR-plasmids since several other replicons also use the same kind of proteins, with some differences, like those found the IncQ plasmids that encode their own DNA primase ${ }^{48}$, or in the IncW plasmid family that encode a relaxase with DNA helicase activity ${ }^{49}$. Replication by the RC mode can be succinctly schematized (Figure 1): the Rep initiator protein recognizes its cognate dso on the leading strand and induces hairpin extrusion on a curved region of the supercoiled DNA substrate ${ }^{39,50}$ (Figure 1A). The Rep initiator has site-specific endonuclease nicking-closing activities, and cleaves the phosphodiester bond of a definite dinucleotide, leaving a 3'-OH end while the protein remains bound to the 5'end of the cleaved strand (Figure 1B). The nick generated by the Rep initiator is elongated by host-encoded proteins (DNAP, a helicase, and SSB). As the replisome progresses, it displaces the parental leading strand that is replaced by the newly synthesized strand. The end products of this stage (Figure 1C) are a double stranded (ds) DNA molecule that has one parental and one newly synthesized strand and a ssDNA intermediate ${ }^{40,51,52}$. Further, the Rep protein is released as an inactive heterodimer (Rep::Rep::DNA) composed of one intact Rep molecule and one modified subunit which has a short oligonucleotide covalently bound to it ${ }^{53}$. The half replicated molecule would be supercoiled by the host DNA gyrase, leaving a plasmid 
copy ready for the next round of replication (Figure 1C). In addition, the singlestranded DNA (sSDNA) intermediate (that would be coated by SSB) is converted to a dsDNA molecule by lagging strand synthesis (Figure 1D). This starts from the sso that, upon hairpin generation on ssDNA, would generate a so-called 'ssDNA promoter' ${ }^{54}$. From this promoter, the host RNAP synthesizes a short RNA primer that is elongated by the DNAP I, to be most likely replaced later by DNAP III ${ }^{41}$ (Figure $1 \mathrm{E})$. Thus, the end-product of the lagging strand synthesis is a hemireplicated dsDNA molecule that would be supercoiled by the host DNA gyrase (Figure 1F). In-depth reviews on replication by the $\mathrm{RC}$ mechanism have been published along the years ${ }^{12}$, $35,36,45,55-57$

\section{CONTROL AND DISTRIBUTION OF PLASMID COPY NUMBERS}

Stable plasmid inheritance can be achieved by several means such as, at least: i) integration into the host chromosome so that the plasmid copy number is identical to that of the chromosome ${ }^{58}$; ii) incorporating into the plasmid backbone some genes that participate in plasmid stable inheritance, like those belonging to the toxinantitoxin categories ${ }^{59}$, iii) incorporating partitioning systems ${ }^{60-62}$, and iv) reducing their size and increasing their number of copies so that the probability of plasmid loss is reduced ${ }^{13}$. RCR-plasmids are included in the latter case. These plasmids ensure their stable inheritance because of their elevated number of copies ( $20-30$ copies per chromosome equivalent in the original host). Further, RCR-plasmids do not seem to carry specialized partitioning systems with the exceptions reported for RCRplasmids from Bacillus thuringiensis ${ }^{37}$, so that their copy number $(N)$ seems to be distributed randomly between daughter cells at the time of division ${ }^{22,55}$. Control of RCR-plasmid replication is exerted at the initiation level and, in the known cases, and it is executed by either asRNAs or by an asRNA and a transcriptional repressor protein ${ }^{63,64}$. However, more complex situations involving cross-talks between the mobilization module and copy number control elements have been found since the MobM relaxase of plasmid pMV158 actively participates in the copy number control of the plasmid by hindering transcription of the asRNA that negatively regulates synthesis of the RepB initiator ${ }^{65}$. In the best-known examples of asRNAs involved in copy number control, their coding sequences overlap the sense mRNA encoding the Rep initiator but are transcribed in the opposite direction. Thus, these asRNAs were termed 'counter-transcribed' (ct) RNAs, and they will be referred as such here ${ }^{64}$.

Bacterial populations of cells harbouring plasmids without partition systems, like most RCR-plasmids, distribute their copies between daughter cells in a random mode. Consequently, they can be described as having a Gaussian distribution of the cell numbers versus plasmid copy number (discussed in ${ }^{28}$ ). In these plasmids, it could be argued that individual cells may differ in the $N$ values, but from the formal point of view, a Gaussian distribution of copies within the bacterial population is acceptable. It follows that the width of the Gaussian curve may be broad or narrow, indicative of a more or less even distribution of the average copies per cell $\left(N_{\mathrm{av}}\right)$. When the distribution is too broad, the probability of cells having a reduced $N$ value would be high. In this case, the plasmids located to the left of the Gaussian curve would have $N \ll N_{\text {av }}$ before cell division, and the probability of appearance of plasmid-free cells (that usually have a doubling time slightly shorter than that of the plasmid-containing cells) would be higher than in the cases where the width of the 
Gaussian distribution is narrow (Figure 2A). However, mechanisms designed to correct fluctuations in the $N_{\mathrm{av}}$ do exist and are mediated by the regulatory control elements, like the ctRNAs that participate in the increase or decrease of the rate of replication ${ }^{66}$. We can derive the conclusion that RCR-plasmids, due to their relatively high $N_{\text {av }}$ values, should be stably inherited without the need for specialized partitioning systems. This has proved to be correct, except in plasmids in which the lagging strand origin(s) were deleted or were functionally inefficient, showing segregational instability ${ }^{67}$. The experimental rate of plasmid loss per cell and generation $\left(L_{e x}\right)$ was determined based on the equation:

$$
f_{+}=\left(1-L_{e x}\right)^{n+1}
$$

where $f_{+}$is defined as the fraction of plasmid-harbouring cells after $n$ generations in the absence of selective pressure, for instance, an antibiotic-resistance determinant $26,67,68$. These parameters can be experimentally determined by growing a culture for several generations in the presence of selective pressure, followed by recollection of the cells by centrifugation, dilution in antibiotic-free medium for several generations more and determination of the total number of cells (plating in antibiotic-free medium) and the number of cells that still harbours plasmids (plating in antibiotic-containing medium). More recently, microscopy-based approaches to screen for plasmid-free cells at short time intervals ${ }^{69}$ have permitted the measurement of plasmid loss rates and to conclude that these rates were lower than those previously determined at least for plasmid R1 ${ }^{17}$. The mathematical analysis of these and fitness processes of RCR-plasmids have been reported $26,29,70$. When the plasmid is fully stable, the $N$ value remains more or less constant along the generations and, in this case, $N \sim N_{\text {av }}$ and $L_{e x} \sim 0$. Plasmids that do not replicate efficiently in a given host may exhibit an increased instability and then $L_{e x}>0$ and they would be rapidly lost from the population (Figure 2B).

On the other hand, when a plasmid colonizes a new plasmid-free host (either by transformation or mobilization), the intracellular concentration of the negative regulators would not exist; thus the incoming plasmid would over-replicate unhindered, reaching a value of $N \gg N_{\mathrm{av}}$ (Figure 2C). Then, the control functions would operate to regulate the fluctuations in $N$ until the $N_{\text {av }}$ value is reached. This is a typical dose-response fluctuating behaviour that was early studied by System Biology approaches ${ }^{71}$. Small fluctuations in the steady-state would be corrected by the participation of the ctRNAs because they have a short half-life ${ }^{72}$. This may not be the case when the host already harbours a resident plasmid: in these cases, the entering plasmid may find difficulties to establish itself if the resident plasmid encodes a transcriptional repressor protein that may interfere with the synthesis of the Rep protein. This has been shown for the RCR-plasmid pMV158 and, although with a different regulatory circuit, for the theta-replicating plasmid R1 ${ }^{70}$. Measurements of the $N_{\text {av }}$ values are usually referred to a bacterial host genome equivalent. This was early done by extracting total DNA of plasmid-harbouring cultures and densitometric scanning of images of stained agarose gels ${ }^{73,74}$ and by radioactive labelling of exponentially growing cultures of cells-harbouring plasmids ${ }^{75}$. More recent approaches include quantitative real-time PCR ${ }^{70,76}$, and super-resolved location microscopy ${ }^{77}$. 
A
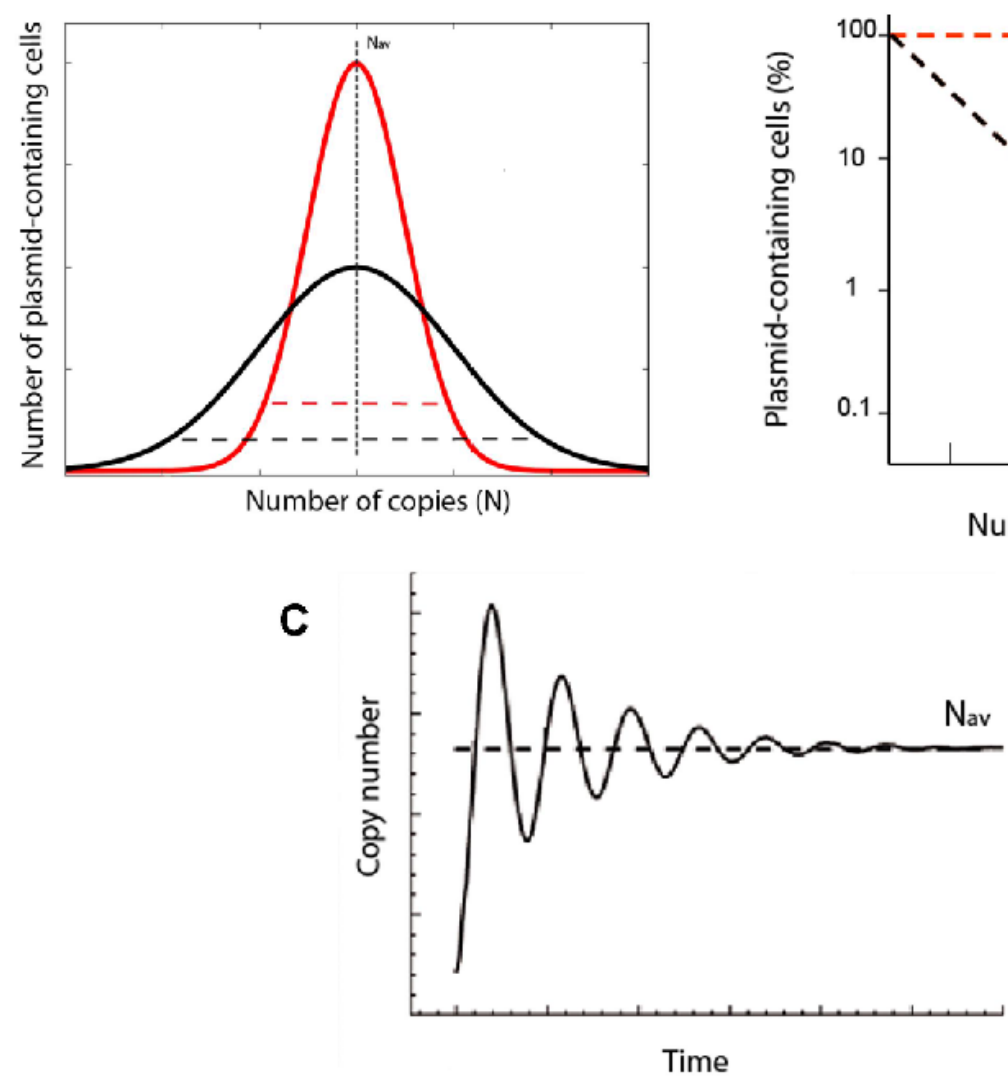

B

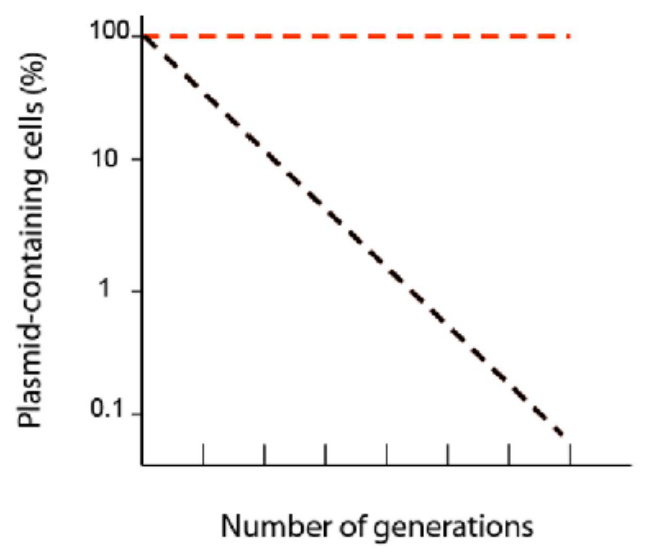

FIGURE 2 Features of plasmid copy numbers in their bacterial hosts. A. The theoretical distribution of plasmid copy numbers at the moment of cell division is provided by a Gaussian curve, in which the $N_{\mathrm{av}}$ is indicated by a vertical dotted line. Plasmids having a narrow distribution (red) will have more probabilities to exhibit a stable inheritance than plasmids with a broad distribution (black). B. Rate of plasmid loss in cultures grown during $n$ generations in the absence of selective pressure. Stable (red line) and unstable (black line) plasmid inheritance are depicted. C. Copy number fluctuations in the $N_{\mathrm{av}}$ of a plasmid following colonization of a new bacterial host.

Individual plasmid copies are randomly selected for replication from a pool of molecules that most likely include nonreplicated copies ${ }^{22,55}$, because the newly replicated ones may need supercoiling by DNA gyrase before they are ready for a new round of replication (Figure 1). Random selection of the molecules that will replicate, in conjunction with the negative control of replication, leads to the concept that two plasmids sharing the same replicon would be unable to co-exist within the same cell in the absence of selective pressure. This would result in the segregation of the two plasmids within the bacterial population, a well known and important process termed plasmid incompatibility ${ }^{13,21,78}$. Incompatibility was a way to classify plasmids before the studies of the Rep proteins and mechanisms of replication ${ }^{79}$ and has been useful in many experimental approaches to plasmid biology (see the sidebar).

Mechanisms to control the $N$ value in the RCR-plasmid family have been described in-depth for two plasmids, pMV158 and pT181. Other examples, less studied, will be also described below. So far, two main mechanisms appear to exist in 
controlling replication of these plasmids: transcriptional attenuation by ctRNAs (Rep_trans; pT181; Figure 3A) and transcriptional repression by a protein plus posttranscriptional repression by a ctRNA (Rep_2; pMV158; Figure 3B).
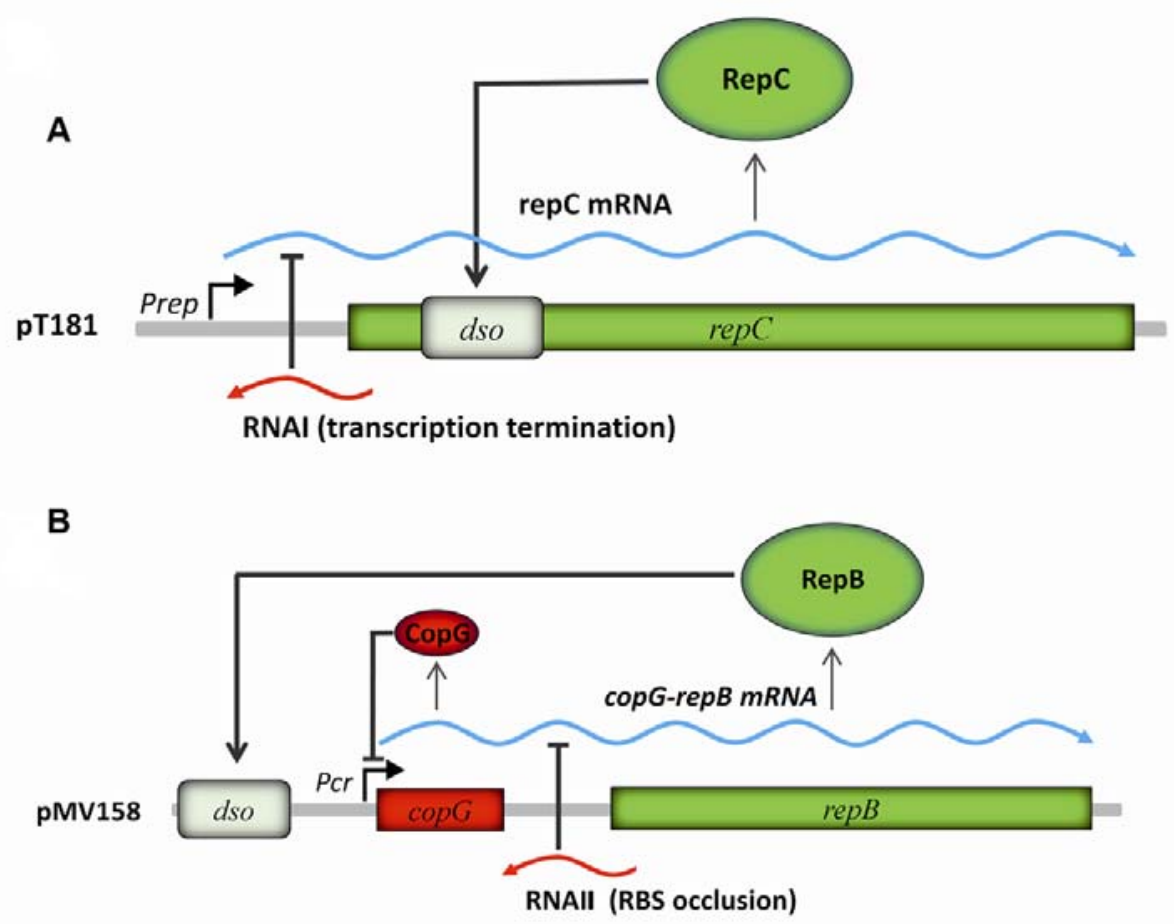

FIGURE 3 Regulatory circuits of RCR-plasmids pT181 and pMV158. A. In the case of pT181, promoter $P_{\text {rep }}$ directs synthesis of the RepC initiator (green ellipse), which initiates replication by binding to its cognate dso. Replication is controlled by RNAI (red) that is complementary to the untranslated 5'-end of the repC mRNA. B. For pMV158, the circuit is regulated by the replication initiator protein RepB (green ellipse) that initiates replication by binding to the dso and cleaving the phosphodiester bond of a specific dinucleotide, leaving a $3^{\prime}-\mathrm{OH}$ end that acts as the replicative primer (see also Fig. 1). The negatively-acting elements (red) are the transcriptional repressor protein CopG and the antisense RNAll. The mechanism for controlling synthesis of RepB is provided by both elements: CopG represses synthesis of the initiator by binding to the $P_{\text {cr }}$ promoter, whereas binding of RNAll to the copG-repB mRNA leads to inhibition of the binding of the ribosomes in the mRNA.

\section{Copy number control by ctRNA}

Pioneer work performed in Novick's laboratory demonstrated that copy number control of the staphylococcal RCR-plasmid pT181 was exerted by limiting the synthesis of the initiator RepC protein. Control was shown to be attained at the transcriptional level by two short-lived ctRNAs, termed RNAI and RNAll, which are transcribed from the same promoter; thus, the two ctRNAs share the same 5'-end, but they have different lengths, 85 and 150 nucleotide (nt)-long, respectively ${ }^{80-82}$. These two ctRNAs are transcribed in opposite direction of the gene encoding the $\mathrm{RepC}$ initiator, being complementary to the untranslated 5'-end of the leader repC 
mRNA (Figure 3A). Thus the repC mRNA and the ctRNAs can pair ('kiss') to generate a duplex RNA. Generation of a full duplex does not seem to be needed to hinder the expression of the repC mRNA because inhibition of the synthesis of RepC seems to be accomplished faster than generation of a fully stable duplex RNA ${ }^{83}$. However, determination of the rate constants of formation of the stable RNA duplex were similar to those of the inhibition of repC synthesis ${ }^{84}$, leaving open this question on the mechanism of the inhibitory process. Generation of the kissing complex requires the existence of a time window when the sense-antisense RNA can find each other; after this period, the repC mRNA adopts a structure, inaccessible to the ctRNAs, that would place the repC ribosome-binding site in a position accessible to the translation machinery (Figure 4). However, along the time-frame where the ctRNAs can bind to the repC mRNA, pairing would lead to the generation of a secondary structure on the mRNA that would resemble a Rho-independent transcription terminator upstream of the initiation codon of the repC gene. As a consequence, premature transcription termination of the essential repC mRNA would occur with the concomitant release of non-productive repC mRNA molecules (Figure 4) 22 .

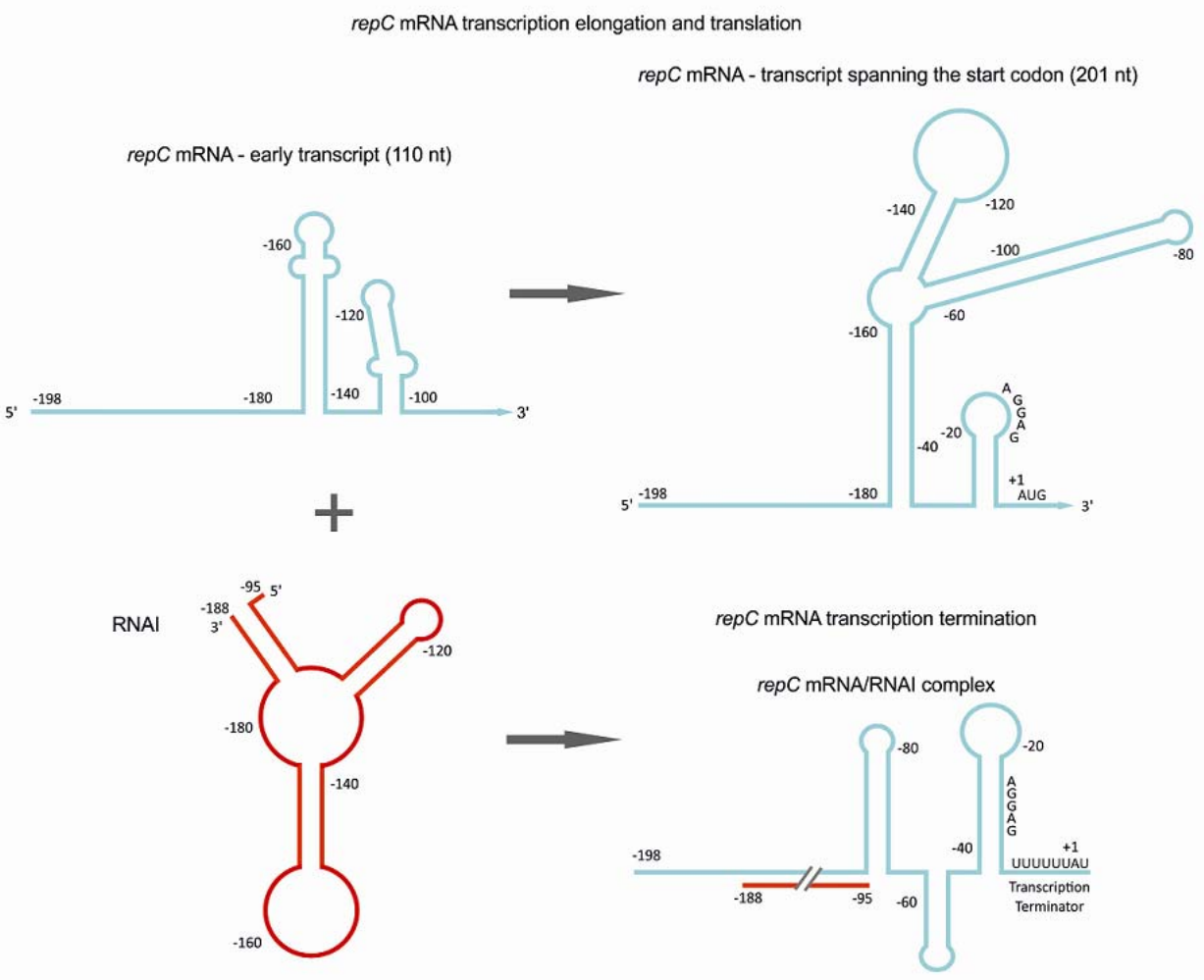

FIGURE 4 Regulatory circuit of plasmid pT181 indicated by a schematic representation of the interactions between the ctRNA (RNAI, red) and the repC mRNA (cyan). The early transcript ( 110 nt-long) of the repC mRNA would fold as having two main hairpins. In the absence of RNAI, the late transcript would pleat as a complex structure that would place the RBS and the repC initiation codon accessible to the translating ribosomes (upper part of the diagram). However, and within a time-window, pairing between the complementary loops of the hairpins generated in the repC mRNA and RNAI molecules may take place. In this case, generation of a hybrid RNAI and mRNA would lead to profound conformational changes in the duplex RNA. In this case, the downstream region of the duplex would generate a new hairpin ending in a 5'-UUUUUUAU-3' 
sequence with the configuration of a Rho-independent transcription terminator. The result would be an untranslated truncated RNA duplex (lower part).

Later studies showed that the longer RNAll could be the result of a readthrough, and thus a minority by-product of RNAl ${ }^{84}$, but essentially the transcriptional attenuation mechanism for controlling $N_{\text {pT181 }}$ by RNAl remained unquestioned. A similar regulatory circuit to that of pT181 was early predicted for the staphylococcal plasmid pC221 ${ }^{85}$ but, to our knowledge, no experimental data has been published.

In the case of the staphylococcal RCR-plasmids of the Rep 1 family, pC194 and pUB110 ${ }^{86}$, two ctRNAs have been proposed to control the synthesis of the initiator proteins, RepA and RepU, respectively. Such control would be exerted at the translational level by binding to the initiation of translation signals of the rep mRNA ${ }^{87}$, ${ }^{88}$. A similar situation was proposed to exist for the staphylococcal plasmid pE194 ${ }^{89}$. In the case of pUB110, self-regulation of the repU gene by the RepU initiator added another level of regulation of $N_{\text {pUB110 }}{ }^{90}$. However, detailed knowledge of the mechanisms involved in the copy number control in these plasmids needs further experimentation.

Synthesis of a 115-nt long ctRNA was demonstrated in the case of the 2.9-kb long streptococcal RCR-plasmid pt38 ${ }^{91}$. The start site of transcription of this ctRNA was shown to be placed at the proper distance from its putative promoter; thus, the ctRNA would overlap the plasmid rep mRNA. If this were the case, a mechanism of inhibition of the translation of the Rep initiator protein could be achieved by pairing of the complementary regions of the ctRNA and the rep mRNA, thus blocking the access of the ribosomes to their binding site.

\section{The double regulatory circuit of plasmid pMV158}

The first instance of a plasmid having a regulatory circuit integrating a transcriptional repressor protein and a ctRNA was that of the RCR-plasmid pMV158 ${ }^{63,73}$. The copy number control of this plasmid is exerted by the concerted action of the $48 \mathrm{nt}$-long ctRNA, termed RNAII ${ }^{66}$, and the 45-amino acid transcriptional repressor protein CopG ${ }^{92}$. The genetic organization of the control region (Figure $3 \mathrm{~B}$ ) shows that the genes encoding the repB initiator and the repressor copG are co-transcribed, although there is no coupled translation of both proteins ${ }^{93}$. The coding region of gene copG is preceded by a near-consensus ribosome binding site (RBS) sequence 75. Protein CopG binds to a palindromic region that encompasses the single $P_{\mathrm{cr}}$ promoter inducing a severe bend in the DNA of $\sim 120^{\circ}{ }^{94}$, and thus hindering the binding of the host RNAP to the promoter or even expelling the already bound RNAP 95

The coding region of gene repB is preceded by a $60 \mathrm{nt}$-long non-coding region encompassing a translation initiation region (TIR). In late $80 \mathrm{~s}$, it was suggested that the following consensus sequence (nucleotides -23 to +3 with respect to the start of the coding region): 5'-AUUUCU...4-5 nt ...UAUA- 9-10 nt ... AUG-3' may be responsible for ribosome binding and therefore the sequence was termed 'atypical' ribosome binding site (ARBS) ${ }^{96,97}$, however the molecular details of ARBS binding to the 3' tail of ribosomal 16S RNA (5'-ACCUCCUU-3'; anti Shine-Dalgarno; aSD) or to 
an alternative ribosomal element remained unclear. In the case of the pneumococcal dpnM gene the ARBS sequence was reported to be a -10 extended promoter ${ }^{98}$. Further, the repB 5'-UTR sequence, and in particular its part proximal to the start codon, was shown to play an important role in the RNAll::copG-repB mRNA interactions ${ }^{66,93}$. In the absence of toeprinting analyses ${ }^{99}$ that would unambiguously show the ribosome-binding site in the repB mRNA, we would like to propose an alternative or complementary, yet unproved, hypothesis that would consider the ribosome-binding site to be a weak version of the Shine-Dalgarno sequence (wSD), while the rest of the conserved sequence of the repB 5-'UTR (including the proposed ARBS) would form a structured RNA element that is responsible for the initial mRNA - ribosome interactions. Formation of specific structured motifs upstream the start codon (as predicted for $\operatorname{repB} \mathrm{mRNA}$ ) has been shown to be involved in the wSD recognition by the ribosome through $S 1$ protein binding to and unfolding of the structured RNA elements ${ }^{100}$. A sequence alignment of the putative rep genes translation initiation region (TIR) of the pMV158 plasmid family indicated the presence of a putative wSD 5'-AGGU-3' (5'-GGGU-3' in pMV158 repB) motif, namely: $\quad \mathrm{RN}(\mathrm{W})_{1-2} \mathrm{RWUWNW}(\mathrm{N})_{0-5} \mathrm{URAGGU}(\mathrm{N})_{1-2}$ AUUAUANC(W) $)_{0-2}(\mathrm{U})_{0-1}$ AUG (adapted from ${ }^{93}$; shown are nucleotides with at least $75 \%$ conservation; in bold positions with at least $90 \%$ conservation; the sequence of RNAIl -10 promotor is shown in italics; the start codon is underlined; $N$ : $A / G / C / U ; R: A / G ; W: A / U)$. Secondary and tertiary structure prediction of the repB mRNA region from nucleotides -60 to +40 , strongly suggests the possibility of generation of three hairpins, which could be further engaged in pseudoknot interactions, including kissing-loop pseudoknots. In our proposed structural model of the repB 5'-UTR (Figure 6), the wSD 5'-GGGU-3' and the start codon AUG sequences are embedded within a bulged hairpin 2. The hairpin 2 loop is made of a long stretch of conserved bases (5'-AUUAUACUU-3') that form a kissing-loop interaction with hairpin 1 loop (5'GGCA-3'; Figures 5 and 6). Formation of alternative structures by hairpin 2-loop would be also possible: a pseudoknot with the hairpin 1 - hairpin 2 linker (5'AAGUCAA-3') or a kissing-loop with the hairpin 3-loop (5'-AAGAUA-3'; Figure 5). In our proposed hypothesis, the conserved motifs of repB mRNA would generate a structure that would interact with the ribosomes through $\mathrm{S1}$ protein. This structure would subsequently be unfolded by the $S 1$ protein leading to repB the wSD motif (bases -16 to -13 ) pairing with the 5' part of the 16S anti-SD sequence (5'-ACCU-3' of 5'-ACCUCCUU-3') and placement of the start AUG codon in the ribosome decoding center. Contribution of SD sequence types (including lack of a SD sequence), structured RNA elements, RBS spacer, or translation enhancers to gene expression regulation in prokaryotic systems is becoming better understood in recent years 100-102. Concerning the mechanism of action (Figure 5), RNAll exerts its inhibitory role at the translational level by pairing, at least partially, with its complementary region in the copG-repB mRNA causing its structural switch that occludes the ARBS/wSD sequence from binding to the ribosome ${ }^{66,93}$. 
A

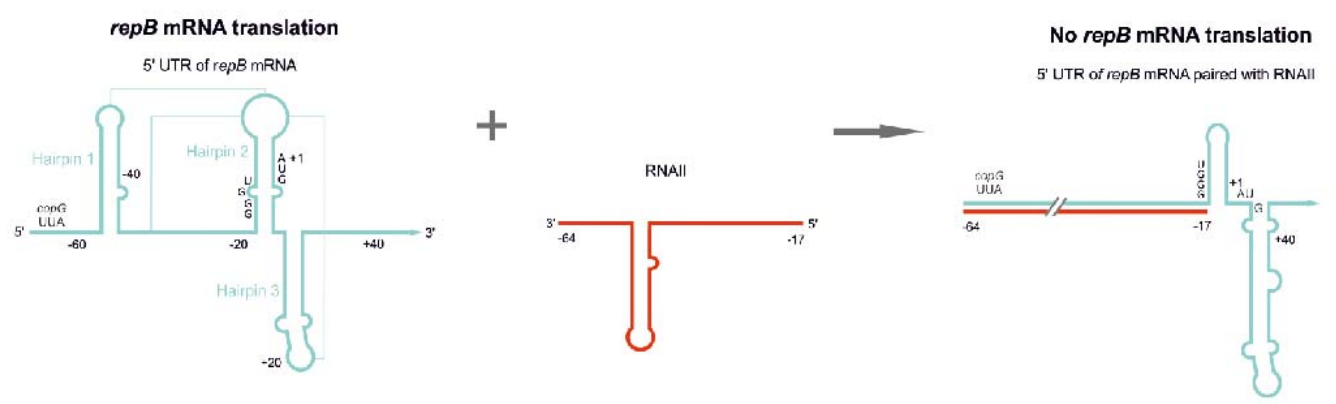

B

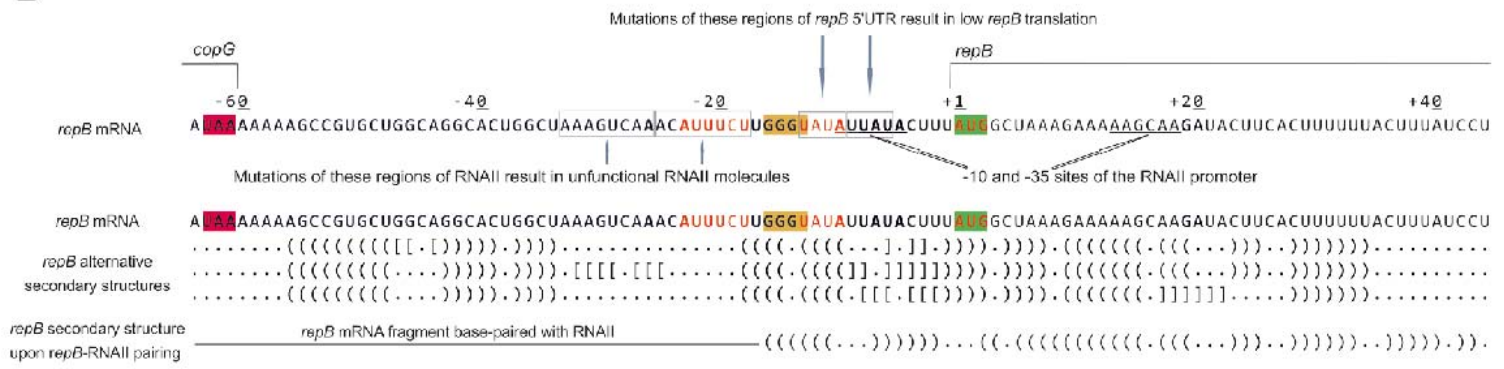

Figure 5. Regulatory circuit of plasmid pMV158. Nucleotide positions with reference to the adenine of the repB AUG start codon are indicated. A. Diagrammatic representation of the secondary structures of repB mRNA (cyan), counter-transcript RNAll (red) and their complex (cyan-red; with // indicating a part of the duplex that is not shown). Thin lines in repB mRNA structure indicate alternative pseudoknots. Upon mRNA/RNAll duplex formation and structural switch of repB mRNA, translating ribosomes would not be able to bind to repB translation initiation site anymore. B. Sequence and secondary structure of repB mRNA. In bold are shown bases with positions conserved at least with $75 \%$ (using an extended nucleotide 'alphabet', where $\mathrm{R}=\mathrm{A} / \mathrm{G}$ and $\mathrm{W}=\mathrm{U} / \mathrm{A}$; alignment from ${ }^{93}$ ). Promoter $P_{\text {ctll }}(-35$ and -10 sequences indicated) directs synthesis of RNAll that starts 17 bases before the start codon of repB (highlighted in green) and terminates past the UAA stop codon of copG (highlighted in red). Red bases indicate ARBS, and bases highlighted in yellow show wSD (GGGU). Boxed regions highlight mRNA and RNAll mutants that show impaired function ${ }^{78,93,103}$. The RNAll transcript $(-17$ to -64$)$ overlaps partially the ARBS/wSD sequences of gene repB. In the lower part of the Figure, a dot-bracket notation of repB mRNA secondary structure (matching brackets symbolize base pairs and dots show unpaired bases) for mRNA alone (with three alternative pseudoknots) and mRNA upon pairing with RNAll are shown.

Synthesis of RNAII is directed by promoter $P_{\text {ctll }}$ that is embedded within the coding sequence of repB (Figure 5B). The entire nucleotide sequence of gene rnall is fully complementary to a region in the copG-repB mRNA that is located upstream of the ARBS/wSD and the AUG initiation codon of repB 66, 78, 103. This genetic organization is conserved in all plasmids of the pMV158 family ${ }^{93}$. Due to the autoregulation of the copG-repB mRNA by CopG, the repressor protein would maintain a fairly constant level of the messenger; on these levels it would operate fluctuating concentrations of RNAll (Figure 3B). Folding of RNAll predicted by the Zuker's algorithm ${ }^{104}$ indicated a simple structure constituted by a single hairpin of 8 paired $\mathrm{nt}$ with a 1-nt internal bulge-loop and a 6 -nt terminal loop $(\Delta G=-10.5 \mathrm{kcal} / \mathrm{mol})$. RNAII is constitutively synthesized, has a short half-life $(\sim 1 \mathrm{~min})$, and being only $48 \mathrm{nt}$-long is one of the smallest ctRNA described so far ${ }^{13,93,103}$. The 3'-end of RNAll extends and terminates past the UAA stop codon of gene copG (Figure $5 \mathrm{~B}$ ), and contains a 
stretch of $14 \mathrm{U}$ residues out of a sequence of $16 \mathrm{nt}$. This 3'-terminal region of RNAll was shown to be, at least in vitro, a rho-independent transcription terminator with a predicted termination efficiency of $85 \%$ and an experimental one of $\sim 87 \% 105,106$. Mapping of the interactions of RNAll with its cognate region in the copG-repB mRNA showed an unexpected scenario: instead of the 'classical' hairpin-kissing interactions through unpaired loop regions, the RNA initial duplex started by pairing of the 5'-end of RNAll with its complementary sequence in the mRNA. These interactions have been also predicted computationally when running 3D structure prediction of mRNARNAll complex (early complex with partially base paired; Figure 6).

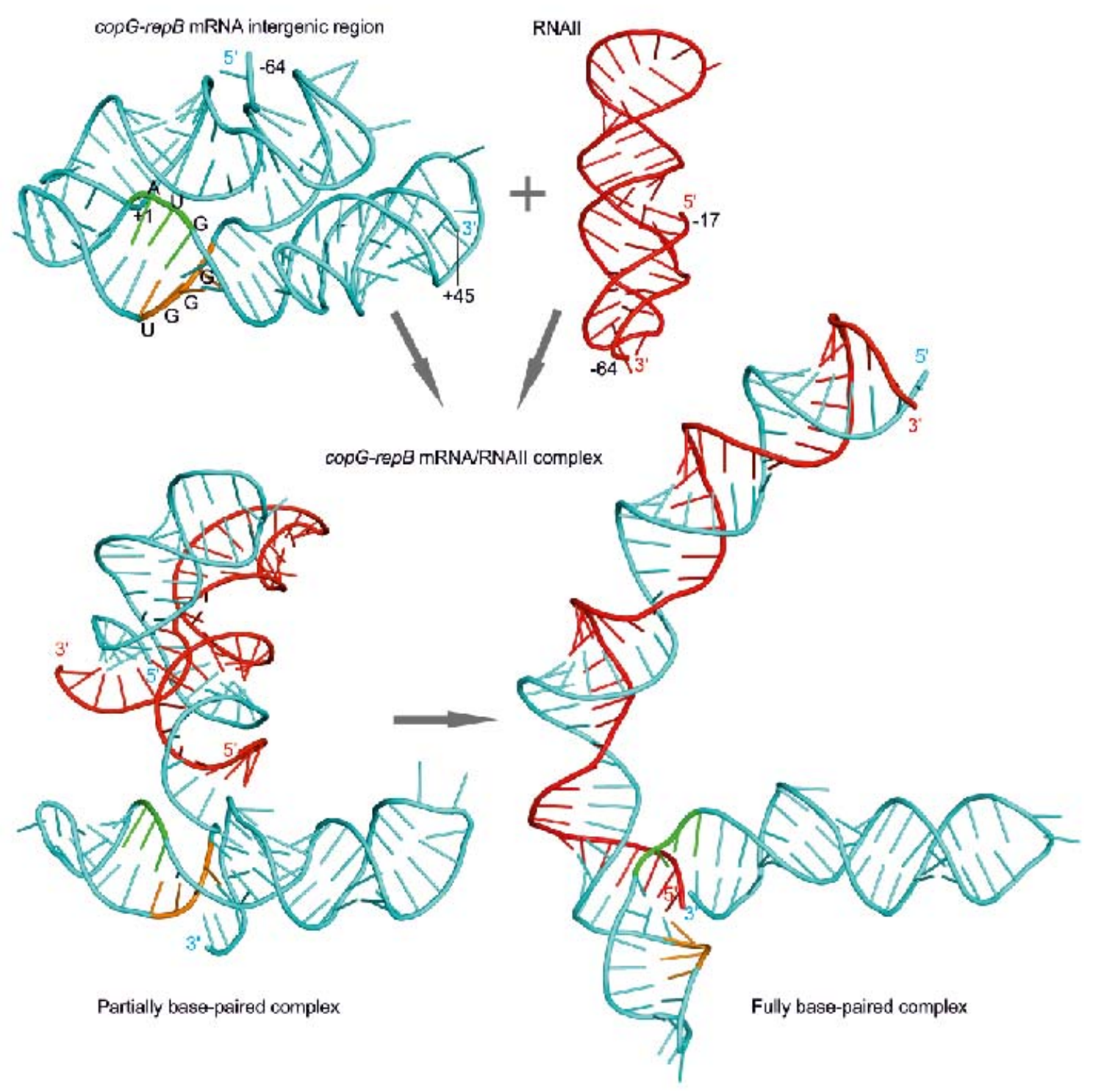

Figure 6 Three-dimensional structural models of pMV158 copG-repB mRNA intergenic region (cyan), RNAll (red), and their early and final complex (all models were submitted to RNArchitecture database ${ }^{107}$ ). The models were predicted by SimRNAweb ${ }^{108}$ with secondary structure inputs as predicted by RNAstructure ${ }^{109}$, and experimentally evaluated (fully for RNAll 
and partially for the mRNA intergenic region) by López-Aguilar in G. del Solar laboratory ${ }^{78,103}$. Figures were generated using PyMol ${ }^{110}$.

Interestingly, during progression of the complex formation the mRNA region that includes ARBS 3'-fragment/wSD undergoes structural rearrangement that could be responsible for the inability of the ribosome to bind the mRNA-RNAll complex and initiate repB translation (final complex; Figure 6). This pairing was helped by generation of kissing hairpins, but progression from the initial duplex to reach the kissing hairpins and, later on, a full duplex molecule, was not required to generate a stable RNAll-mRNA complex ${ }^{78,103}$. Initial interactions between asRNA and mRNA in several theta-replicating plasmids (like Collb-P9) were shown to be facilitated by a hexanucleotide element that was found to be present in several asRNA ${ }^{111}$. This element termed the 'U-turn' is located at the loop of RNA hairpins and enhances the interactions between sense and asRNAs ${ }^{112,113}$. The U-turn motif was not present in the plasmids of the pMV158 family ${ }^{103}$, suggesting an important difference in the initial stages of the asRNA-mRNA interactions between these RCR-plasmids and those using the kissing hairpins pathway ${ }^{83}$. Further, lack of U-turns could be related to the non-essentiality of an initial kissing complex, at least in plasmids of the pMV158 family ${ }^{114}$. Nevertheless, and whatever the mechanism is, it is interesting to point out that the rates of asRNA-mRNA association constants were similar in plasmids having or lacking the U-turn ${ }^{103}$.

Generation of mutations in either copG or rnall genes followed by incompatibility tests showed that the combination of the two elements exhibited an incompatibility greater than that exerted by either element alone. This synergistic effect points to an important role of CopG-mediated repression/derepression of the operon to regulate the control of $N_{\text {pMV158 }}{ }^{66}$. When an entering pMV158 encountered high levels of CopG (provided by a compatible plasmid), there was a strong decrease in the frequency of plasmid establishment ${ }^{70}$. Repopulation experiments ${ }^{72}$ in which the $N$ value was determined at different times after plasmid DNA uptake allowed to determine the kinetics of plasmid repopulation ${ }^{70}$. The results showed that the process lasted $\sim 45$ min after plasmid transfer (by transformation or conjugation) when CopG was absent from the recipient cells, whereas the presence of intracellular repressor protein dramatically diminished the repopulation of the cells by plasmid pMV158, but not by plasmids lacking the CopG-RNAll regulatory circuit ${ }^{70}$. A similar hindrance in plasmid establishment was found in plasmid R1 that has a different regulatory pathway but also encodes a transcriptional repressor protein (CopB) involved in copy number control ${ }^{115}$.

Summing up, and lacking more detailed experiments, we can advance the following conclusion: out of the three RCR-plasmid families, Rep_trans, Rep_1, and Rep_2, represented by plasmids pT181, pUB110/pC194, and pMV158, respectively $43,45,57$, differences in the mechanisms controlling their number of copies seem to exist: i) Rep_trans and Rep_1 plasmids control their number of copies only by transacting ctRNAs, although regulation of the levels of rep mRNA by the Rep initiator itself could also participate in the regulatory circuit; and ii) Rep_2 plasmids would integrate two elements within a single circuit: a ctRNA and a CopG-like transcriptional repressor protein. Both elements are active in trans and would jointly participate in the regulatory circuit ${ }^{13,45,114}$. 


\section{POSSIBLE APPLICATIONS AND FUTURE DIRECTIONS}

Ample knowledge has accumulated over the years on the mechanisms employed by asRNAs to control plasmid replication and, hence, to down-regulate gene expression. However, exploitation of this knowledge to develop tools to reduce the expression of genes involved in virulence and/or pathogenicity has been scarce. Reduction in the levels of the staphylococcal alpha-toxin by the use of a regulated asRNA was feasible ${ }^{116}$, but no follow-up information was reported. Nevertheless, employment of asRNA placed under the control of inducible promoters could be an amenable approach to develop 'killer' or silencing vectors designed to regulate synthesis of an antisense region to any desired essential gene leading to cell growth arrest or even cell death. These vectors could be used as possible 'live' vaccines when provided by non-pathogenic bacteria carrying a plasmid vector with high transfer frequencies and that could be eliminated once they have accomplished their immunogenic role $\left({ }^{117}\right.$; Espinosa, unpublished). Alternatives to these strategies have been developed, especially by employment of modified asRNAs coupled to oligodeoxynucleotides to silence essential genes at mRNA::DNA levels. Paired DNA::RNA molecules are prone to degradation by intracellular nucleases, and variants of these molecules have been developed especially peptide-nucleic acids ${ }^{118}$. These compounds, termed PNAs, are analogues of nucleic acids but the sugar-phosphate backbone is substituted by a flexible peptide polymer to which the bases are attached. Thus, PNAs can mimic and pair to DNA or RNA, generating heteroduplexes resistant to degradation by intracellular enzymes. All these approaches have a fundamental drawback that is the delivery of the compound into a clinical format ${ }^{119}$, although alternatives have been found and clinical trials are in progress as recently reviewed 120. Importantly, just when this review was being finished, the Journal Nucleic Acids Research has launched a special issue gathering selected articles on nucleic acids therapeutics

(https://academic.oup.com/nar/pages/nucleic_acids_therapeutics_collection).

Concerning future directions, we envisage at least three, in addition to the above. Firstly, in the drug discovery field, it has been found a very promising approach that consists in developing asRNA molecules to which membranepenetrating peptides (MPPs) have been coupled. MPPs are short molecules ( 40 residues) that have an access to the intracellular space of any living cell. This is because they are highly cationic and rich in arginine and lysine residues, thus being able to carry with them conjugated molecules, nucleic acids among them. Therefore, MPPs are useful molecules to be explored to deliver drugs to the bacterial intracellular milieu ${ }^{121}$. Phosphorodiamidate-morpholino oligonucleotides mimicking a nucleic acid conjugated to one MPP have been successfully used as an active compound against Acinetobacter both in vitro and in vivo ${ }^{122}$. Secondly, there have been important findings of functional microRNA-size RNAs in Escherichia coli ${ }^{123}$, the synthesis of a 20-nt long small microRNA-size encoded by the E. coli phage $\Phi 24 \mathrm{~B}$ that severely alter the expression of phage- and host-genes ${ }^{124}$, and the existence of a secretable microRNA-size in Streptococcus sanguinis ${ }^{125}$. All these novel discoveries on these RNA molecules that are similar to eukaryotic microRNA are yet to be fully explored. And thirdly, we have little information on the cross-talks between chromosomally-encoded proteins and RCR-plasmid regulatory networks. A recent 
report has shown that out of the three RNase III-homologs encoded by the cyanobacterium Synechococcus sp. strain PCC 7002, one of them is specifically dedicated to cleavage of the ctRNA involved in the control of the number of copies of the indigenous RCR-plasmid PAQ3 ${ }^{126,127}$, a member of the pMV158 plasmid family. These novel findings open an unexplored avenue of research aimed to unveil the processes of cross-talks between bacteria and their RCR-plasmids, something that we have just started to discover, but not to understand yet.

\section{CONCLUSION}

Plasmids constitute an important part (up to 20\%) of the bacterial pangenome ${ }^{128}$ and as such participate actively in the response to selective pressures: they play a key role in the spread of antibiotic resistances or in the acquisition of catabolic pathways in response to toxic compounds in soils and waters ${ }^{129,130 . ~ B e i n g ~ s h a r e d ~ a m o n g ~}$ different bacterial groups, many plasmids move around posing some 'background noise' in the sequence databases. And furthermore, plasmids have played a fundamental role in the development of the modern Biology, not only as cloning and/or expression vectors but also in the development of tools for Synthetic Biology 131. Now that the basic studies in Plasmid Biology appear to dwindle, it is the time to revisit many of the fundamental studies dealing with the control of plasmid replication by asRNAs. The basic questions being: i) do we know everything that is needed to know? And, if not, ii) what do we need to know? Cross-talks between plasmid modules, plasmid copies, and plasmids and chromosomes come immediately to our minds. Understanding the mechanisms of plasmid horizontal transfer will require further efforts if we want to control the spread of antibiotic-resistances. And, of course, asRNAs can be useful tools in the design of novel targets and strategies to deal with pathogenic bacteria. We should use technologies like single-cell, microfluidics, RNAseq, and global approaches to understand the mechanisms underlying why and how the replicative machinery must be controlled and to fully understand the role of asRNAs in these processes.

\section{ACKNOWLEDGEMENTS}

Thanks are due to Gloria del Solar and Ramón Díaz-Orejas for many years of fruitful collaboration, to the latter for his critical reading of the manuscript, and to the three unknown reviewers that greatly improved the manuscript.

\section{REFERENCES}

1. Itoh T, Tomizawa J. Formation of an RNA primer for initiation of replication of ColE1 DNA by ribonuclease H. Proc. Natl. Acad. Sci. USA 1980, 77:2450-2454.

2. Som T, Tomizawa J. Regulatory regions of ColE1 that are involved in determination of plasmid copy number. Proc. Natl. Acad. Sci. USA 1983, 80:2257-2261.

3. Ren Y-J, Zhang Y. An update on RNA interference-mediated gene silencing in cancer therapy. Expert Opinion on Biological Therapy 2014, 14:1581-1592.

4. Chappell J, Takahashi MK, Lucks JB. Creating small transcription activating RNAs. Nature Chemical Biology 2015, 11:214-220. 
5. Westbrook AM, Lucks JB. Achieving large dynamic range control of gene expression with a compact RNA transcription-translation regulator. Nucleic Acids Research 2017, 45:5614-5624.

6. Thomas CM, Nielsen KM. Mechanisms of, and barriers to, Horizontal Gene Transfer between bacteria. Nat. Rev. Microbiol. 2005, 3:711-721.

7. Yu JS, Noll KM. Plasmid pRQ7 from the hyperthermophilic bacterium Thermotoga species strain RQ7 replicates by the rolling-circle mechanism. Journal of Bacteriology 1997, 179:7161-7164.

8. Akimkina T, Ivanov P, Kostrov S, Sokolova T, Bonch-Osmolovskaya E, Firman K, Dutta CF, McClellan JA. A highly conserved plasmid from the extreme thermophile Thermotoga maritima MC24 is a member of a family of plasmids distributed worldwide. PLASMID 1999, 42:236-240.

9. Galvão TC, Mohn WW, de Lorenzo V. Exploring the microbial biodegradation and biotransformation gene pool. Trends in Biotechnology 2005, 23:497-506.

10. González V, Bustos P, Ramírez-Romero MA, Medrano-Soto A, Salgado H, Hernández-González I, Hernández-Celis JC, Quintero V, Moreno-Hagelsieb G, Girard L, et al. The mosaic structure of the symbiotic plasmid of Rhizobium etliCFN42 and its relation to other symbiotic genome compartments. Genome Biology 2003, 4:R36.

11. Thomas CM, Summers D. Bacterial Plasmids. In: eLS: John Wiley \& Sons, Ltd; 2001.

12. del Solar G, Giraldo R, Ruiz-Echevarría MJ, Espinosa M, Díaz-Orejas R. Replication and control of circular bacterial plasmids. Microbiol. Mol. Biol. Rev. 1998, 62:434-464.

13. del Solar G, Espinosa M. Plasmid copy number control: an ever-growing story. Mol. Microbiol. 2000, 37:492-500.

14. Brantl S. Plasmid replication control by antisense RNAs. Microbiology Spectrum 2014, 2.

15. Blomberg P, Nordstrom K, Wagner EGH. Replication control of plasmid R1: RepA synthesis is regulated by CopA RNA through inhibition of leader peptide translation. EMBO J. 1992, 11:2675-2683.

16. Nordström K, Wagner EGH. Kinetic aspect of control of plasmid replication by antisense RNA. Trends Biol. Sci. 1994, 19:294-300.

17. Nordström K. Plasmid R1-Replication and its control. Plasmid 2006, 55:1-26.

18. Pritchard RH. Control of DNA replication in bacteria. In: Kohiyama IMM, ed. DNA synthesis: present and future. New York: Plenum Press; 1978, 1-22.

19. Nordström K. Control of plasmid replication. Plasmid 1983, 9:1-7.

20. Nordström K. Control of plasmid replication: theoretical considerations and practical solutions. In: D.R. Helinski SNC, D.B. Clewell, D.A. Jackson, and A. Hollaender (ed), Plenum Press. New York., ed. Plasmids in bacteria.; 1985, 189-214.

21. Novick RP. Plasmid incompatibility. Microbiol. Rev. 1987, 51:381-395.

22. Novick RP. Staphylococcal plasmids and their replication. Annu. Rev. Microbiol. 1989, 43:537-565.

23. Pritchard RH. Review lecture on the growth and form of a bacterial cell. Philos. Trans. R. Soc. Lond. B Biol. Sci. 1974, 267:303-336.

24. Bouma JE, Lenski RE. Evolution of a bacteria/plasmid association. Nature 1988, 335:351.

25. Lenski RE, Simpson SC, Nguyen TT. Genetic analysis of a plasmid-encoded, host genotype-specific enhancement of bacterial fitness. J. Bacteriol. 1994, 176:31403147.

26. Hernández-Arriaga AM, Espinosa M, del Solar G. Fitness of the pMV158 replicon in Streptococcus pneumoniae. Plasmid 2012, 67:162-166.

27. Summers DK. The kinetics of plasmid loss. Trends in Biotechnology 1991, 9:273-278.

28. Summers DK. The biology of plasmids. Oxford: Blackwell Science Ltd.; 1996.

29. Hernández-Arriaga AM, Espinosa M, del Solar G. A functional lagging strand origin does not stabilize plasmid pMV158 inheritance in Escherichia coli. Plasmid 2000, 43:49-58. 
30. Fernández-López C, Bravo A, Ruiz-Cruz S, Solano-Collado V, Garsin DA, LorenzoDíaz F, Espinosa M. Mobilizable rolling-circle replicating plasmids from Gram-positive bacteria: a low-cost conjugative transfer. Microbiol Spectrum. 2014, 2.

31. Thomas CM. The horizontal gene pool. Amsterdam: Harwood Academic Publishers; 2000.

32. Nešvera J, Hochmannová J, Pátek M. An integron of class 1 is present on the plasmid pCG4 from Gram-positive bacterium Corynebacterium glutamicum. FEMS Microbiology Letters 1998, 169:391-395.

33. Meijer WJJ, van der Lelie D, Venema G, Bron S. Effects of the generation of singlestranded DNA on the maintenance of plasmid pMV158 and derivatives in different Bacillus subtilis strains. Plasmid 1995, 33: 79-89.

34. Jannière L, Gruss A, Ehrlich SD. Plasmids. In: Sonenshein AL, Hoch, J.A., and Losick, R. (eds). Washington. American Society for Microbiology., ed. Bacillus subtilis and other Gram-positive bacteria: Biochemistry, physiology and molecular genetics.; 1993, 625-644.

35. Lorenzo-Díaz F, Fernández-López C, Garcillán-Barcia MP, Espinosa M. Bringing them together: Plasmid pMV158 rolling circle replication and conjugation under an evolutionary perspective. Plasmid 2014, 74:15-31.

36. Espinosa M. Plasmids as models to study macromolecular interactions: the pMV158 paradigm. Res. Microbiol. 2013, 164:199-204.

37. Andrup L, Jensen GB, Wilcks A, Smidt L, Hoflack L, Mahillon J. The patchwork nature of rolling-circle plasmids: comparison of six plasmids from two distinct Bacillus thuringiensis serotypes. PLASMID 2003, 49:205-232.

38. Lorenzo-Díaz F, Fernández-López C, Guillén-Guío B, Bravo A, Espinosa M. Relaxase MobM induces a molecular switch at its cognate origin of transfer. Frontiers in Molecular Biosciences 2018, 5.

39. Ruiz-Masó JA, Lurz R, Espinosa M, del Solar G. Interactions between the RepB initiator protein of plasmid pMV158 and two distant DNA regions within the origin of replication. Nucleic Acids Res. 2007, 35:1230-1244.

40. Gruss AD, Ross HF, Novick RP. Functional analysis of a palindromic sequence required for normal replication of several staphylococcal plasmids. Proc. Natl. Acad. Sci. USA 1987, 84:2165-2169.

41. Kramer MG, Khan SA, Espinosa M. Plasmid rolling circle replication: identification of the RNA polymerase-directed primer RNA and requirement of DNA polymerase I for lagging strand initiation. EMBO J. 1997, 16:5784-5795.

42. Lorenzo-Díaz F, Espinosa M. Lagging strand DNA replication origins are required for conjugal transfer of the promiscuous plasmid pMV158. J. Bacteriol. 2009, 191:720727.

43. Punta M, Coggill PC, Eberhardt RY, Mistry J, Tate J, Boursnell C, Pang N, Forslund K, Ceric G, Clements J, et al. The Pfam protein families database. Nucleic Acids Research 2012, 40:D290-D301.

44. Khan S. Plasmid rolling-circle replication: highlights of two decades of research. Plasmid 2005, 53:126 - 136.

45. Ruiz-Masó JA, Machón C, Bordanaba-Ruiseco L, Espinosa M, Coll M, del Solar G. Plasmid rolling-circle replication. Microbiology Spectrum 2015, 3.

46. Anand SP, Khan SA. Structure-specific DNA binding and bipolar helicase activities of PcrA. Nucl. Acids. Res. 2004, 32:3190-3197.

47. Ruiz-Masó JA, Anand SP, Espinosa M, Khan SA, del Solar G. Genetic and biochemical characterization of the Streptococcus pneumoniae PcrA helicase and its role in plasmid rolling circle replication. J. Bacteriol. 2006, 188:7416-7425.

48. Scherzinger E, Bagdasarian MM, Scholz P, Lurz R, Rhckert R, Bagdasarian M. Replication of the broad host-range plasmid RSF1010: requirement for three plasmid encoded proteins. Proc. Natl. Acad. Sci. USA. 1984, 81:654-658. 
49. Grandoso G, Llosa M, Zabala JC, de la Cruz F. Purification and biochemical characterization of TrwC, the helicase involved in plasmid R388 conjugal DNA transfer. Eur J Biochem 1994, 226:403-412.

50. Koepsel RR, Khan SA. Static and initiator protein-enhanced bending of DNA at a replication origin. Science 1986, 233:1316-1318.

51. te Riele $\mathrm{H}$, Michel $\mathrm{B}$, Ehrlich S. Are single-stranded circles intermediates in plasmid DNA replication? EMBO J 1986, 5:631 - 637.

52. del Solar G, Puyet A, Espinosa M. Initiation signals for the conversion of single stranded to double stranded DNA forms in the streptococcal plasmid pLS1. Nucleic Acids Res. 1987, 15:5561-5580.

53. Rasooly A, Wang P-Z, Novick RP. Replication-specific conversion of the Staphylococcus aureus pT181 initiator protein from an active homodimer to an inactive heterodimer. EMBO J. 1994, 13:5245-5251.

54. Masai H, Arai K. Frpo: a novel single-stranded DNA promoter for transcription and for primer RNA synthesis of DNA replication. Cell 1997, 89:897-907.

55. Novick RP. Contrasting lifestyles of rolling-circle phages and plasmids. Trends Biochem. Sci. 1998, 23:434-438.

56. Khan SA. Plasmid rolling-circle replication: highlights of two decades of research Plasmid 2005, 53:126-136.

57. Wawrzyniak P, Płucienniczak G, Bartosik D. The different faces of Rolling-Circle Replication and its multifunctional initiator proteins. Frontiers in Microbiology 2017, 8.

58. Dempsey LA, Dubnau DA. Identification of plasmid and Bacillus subtilis chromosomal recombination sites used for pE194 integration. J. Bacteriol. 1989, 171:2856-2865.

59. Díaz-Orejas R, Espinosa M, Yeo CC. The importance of the expendable: ToxinAntitoxin genes in plasmids and chromosomes. Frontiers in Microbiology 2017, 8.

60. Austin SJ, Nordström K. Partition-mediated incompatibility of bacterial plasmids. Cell 1990, 60:351-354.

61. Funnell B. ParB partition proteins: Complex formation and spreading at bacterial and plasmid centromeres. Frontiers in Molecular Biosciences 2016, 3:44.

62. Oliva MA. Segrosome complex formation during DNA trafficking in bacterial cell division. Frontiers in Molecular Biosciences 2016, 3.

63. del Solar G, Acebo P, Espinosa M. Replication control of plasmid pLS1: efficient regulation of plasmid copy number is exerted by the combined action of two plasmid components, CopG and RNA II. Mol. Microbiol. 1995, 18:913-924.

64. Kumar C, Novick RP. Plasmid pT181 replication is regulated by two countertranscripts. Proc. Natl. Acad. Sci. USA 1985, 82:638-642.

65. Lorenzo-Díaz F, Fernández-López C, Lurz R, Bravo A, Espinosa M. Crosstalk between vertical and horizontal gene transfer: plasmid replication control by a conjugative relaxase. Nucleic Acids Research 2017, 45:7774-7785.

66. del Solar G, Acebo P, Espinosa M. Replication control of plasmid pLS1: the antisense RNA II and the compact rnall region are involved in translational regulation of the initiator RepB synthesis. Mol. Microbiol. 1997, 23:95-108.

67. del Solar G, Kramer G, Ballester S, Espinosa M. Replication of the promiscuous plasmid pLS1: a region encompassing the minus origin of replication is associated with stable plasmid inheritance. Mol Gen Genet 1993, 241:97 - 105.

68. Gerdes K, Larsen JE, Molin S. Stable inheritance of plasmid R1 requires two different loci. Journal of Bacteriology 1985, 161:292-298.

69. Lau BTC, Malkus P, Paulsson J. New quantitative methods for measuring plasmid loss rates reveal unexpected stability. Plasmid 2013, 70:353-361.

70. Ruiz-Masó JA, Luengo LM, Moreno-Córdoba I, Díaz-Orejas R, del Solar G. Successful establishment of plasmids R1 and pMV158 in a new host requires the relief of the transcriptional repression of their essential rep genes. Frontiers in Microbiology 2017, 8.

71. Espinosa M, Garcia E, Fernaud JM. Mathematical approach to the stimulation of the competence development in Bacillus subtilis. J. Theoretical Biology 1977, 67:155-174. 
72. Highlander SK, Novick RP. Plasmid repopulation kinetics in Staphylococcus aureus. Plasmid 1987, 17: 210-221.

73. del Solar G, Espinosa M. The copy number of plasmid pLS1 is regulated by two trans-acting plasmid products: the antisense RNA II and the repressor protein, RepA. Mol. Microbiol. 1992, 6:83-94.

74. Projan SJ, Carleton S, Novick RP. Determination of plasmid copy number by fluorescence densitometry. Plasmid 1983, 9:182-190.

75. Lacks SA, López P, Greenberg B, Espinosa M. Identification and analysis of genes for tetracycline resistance and replication functions in the broad-host-range plasmid pLS1. J. Mol. Biol. 1986, 192:753-765.

76. Calcuttawala F, Hariharan C, Pazhani GP, Saha DR, Ramamurthy T. Characterization of E-type colicinogenic plasmids from Shigella sonnei. FEMS Microbiology Letters 2017, 364:fnx060-fnx060.

77. Nino D, Rafiei N, Wang Y, Zilman A, Milstein JN. Molecular counting with localization microscopy: A Bayesian estimate based on fluorophore statistics. Biophysical Journal, 112:1777-1785.

78. López-Aguilar C, del Solar G. Probing the sequence and structure of in vitro synthesized antisense and target RNAs from the replication control system of plasmid pMV158. Plasmid 2013, 70:94-103.

79. Cohen SN, Couturier M, del Solar G, Díaz-Orejas R, Espinosa M, Giraldo R, Jánniere L, Miller C, Osborn M, Thomas CM. Plasmid replication and copy number control. In: Thomas CM, ed. The horizontal gene pool: bacterial plasmids and gene spread; 2000.

80. Carleton SM, Projan SJ, Highlander SK, Moghazeh SM, Novick RP. Control of pT181 replication. II. Mutational analysis. EMBO J. 1984, 3:2407-2414.

81. Novick RP, Adler GK, Projan SJ, Carleton SM, Highlander SK, Gruss SA, Khan SA, lordanescu S. Control of pT181 replication. I. The pT181 copy control function acts by inhibiting the synthesis of a replication protein. EMBO J. 1984, 3:2399-2405.

82. Novick RP, Iordanescu S, Projan SJ, Kornblum J, Edelman I. pT181 plasmid replication is regulated by a countertranscript-driven transcriptional attenuator. Cell 1989, 59:395-404.

83. Wagner EGH, Brantl S. Kissing and RNA stability in antisense control of plasmid replication. Trends Biochem. Sci. 1998, 23:451-454.

84. Brantl S, Wagner EGH. Antisense RNA-mediated transcriptional attenuation: an in vitro study of plasmid pT181. Mol. Microbiol. 2000, 35:1469-1482.

85. Projan SJ, Novick RP. Comparative analysis of five related staphylococcal plasmids. Plasmid 1988, 19:203-221.

86. Iordanescu S, Surdeanu M. Interactions between small plasmids in Staphylococcus aureus. Arch. Roum. Pathol. Exp. Microbiol. 1978, 37:155-160.

87. Alonso JC, Taylor RH. Initiation of plasmid pC194 replication and its control in Bacillus subtilis. Mol. Gen. Genet. 1987, 210:476-484.

88. Maciag IE, Viret JF, Alonso JC. Replication and incompatibility properties of plasmid pUB110 in Bacillus subtilis. Mol. Gen. Genet. 1988, 212:232-240.

89. Villafane R, Bechhofer D, Narayan C, Dubnau DA. Replication control genes of plasmid pE194. J. Bacteriol. 1987, 169:4822-4829.

90. Muller AK, Rojo F, Alonso JC. The level of the pUB110 replication initiator protein is autoregulated, which provides an additional control for plasmid copy number. Nucleic Acids Res. 1995, 23:1894-1900.

91. Petrova P, Miteva V, Ruiz-Masó JA, del Solar G. Structural and functional analysis of pt38, a $2.9 \mathrm{~kb}$ plasmid of Streptococcus thermophilus yogurt strain. Plasmid 2003, 50:176-189.

92. del Solar G, Hernández-Arriaga AM, Gomis-Rüth FX, Coll M, Espinosa M. A genetically economical family of plasmid-encoded transcriptional repressors in control of plasmid copy number. J. Bacteriol. 2002, 184:4943-4951. 
93. López-Aguilar C, Ruiz-Masó JA, Rubio-Lepe TS, Sanz M, del Solar G. Translation initiation of the replication initiator repB gene of promiscuous plasmid pMV158 is led by an extended non-SD sequence. Plasmid 2013, 70:69-77.

94. Gomis-Rüth FX, Solá M, Acebo P, Párraga A, Guasch A, Eritja R, González A, Espinosa M, del Solar G, Coll M. The structure of plasmid-encoded transcriptional repressor CopG unliganded and bound to its operator. EMBO J. 1998, 17:7404-7415.

95. Hernández-Arriaga AM, Rubio-Lepe TS, Espinosa M, del Solar G. Repressor CopG prevents access of RNA polymerase to promoter and actively dissociates open complexes. Nucl. Acids Res. 2009, 37:4799-4811.

96. de la Campa AG, Kale P, Springhorn SS, Lacks SA. Proteins encoded by the DpnII restriction gene cassette: Two methylases and an endonuclease. Journal of Molecular Biology 1987, 196:457-469.

97. Lacks SA, Greenberg B, Sabelnikov AG. Possible regulation of DNA methyltransferase expression by RNA processing in Streptococcus pneumoniae. Gene 1995, 157:209-212.

98. Sabelnikov AG, Greenberg B, Lacks SA. An extended -10 promoter alone directs transcription of the Dpnll operon of Streptococcus pneumoniae. J. Mol. Biol. 1995, 250:144-155.

99. Hartz D, McPheeters DS, Green L, Gold L. Detection of Escherichia coli ribosome binding at translation initiation sites in the absence of tRNA. Journal of Molecular Biology 1991, 218:99-105.

100. Duval M, Korepanov A, Fuchsbauer O, Fechter P, Haller A, Fabbretti A, Choulier L, Micura R, Klaholz BP, Romby $\mathrm{P}$, et al. Escherichia coli ribosomal protein $\mathrm{S} 1$ unfolds structured mRNAs onto the ribosome for active translation initiation. PLOS Biology 2013, 11:e1001731.

101. Omotajo D, Tate $\mathrm{T}$, Cho $\mathrm{H}$, Choudhary M. Distribution and diversity of ribosome binding sites in prokaryotic genomes. BMC Genomics 2015, 16:604.

102. Hockenberry AJ, Stern AJ, Amaral LAN, Jewett MC. Diversity of translation initiation mechanisms across bacterial species is driven by environmental conditions and growth demands. Molecular Biology and Evolution 2018, 35:582-592.

103. López-Aguilar C, Romero-López C, Espinosa M, Berzal-Herranz A, del Solar G. The 5 -tail of antisense RNAll of pMV158 plays a critical role in binding to the target mRNA and in translation inhibition of repB. Frontiers in Genetics 2015, 6:225.

104. Zuker M. Mfold web server for nucleic acid folding and hybridization prediction. Nucl. Acids Res. 2003, 31:3406-3415.

105. d'Aubenton-Carafa Y, Brody E, Thermes C. Prediction of Rho-independent Escherichia coli transcription terminators. A statistical analysis of their RNA stem-loop structures. J. Mol. Biol. 1990, 216:835-858.

106. del Solar G, Espinosa M. In vitro analysis of the terminator $T_{/ /}$of the inhibitor antisense rnall gene from plasmid pMV158. Plasmid 2001, 45:75-87.

107. Boccaletto P, Magnus M, Almeida C, Żyła A, Astha A, Pluta R, Bagiński B, Jankowska E, Dunin-Horkawicz S, Wirecki TK, et al. RNArchitecture: a database and a classification system of RNA families, with a focus on structural information. Nucleic Acids Research 2018, 46:D202-D205.

108. Magnus M, Boniecki MJ, Dawson W, Bujnicki JM. SimRNAweb: a web server for RNA 3D structure modeling with optional restraints. Nucleic Acids Research 2016, 44:W315-W319.

109. Bellaousov S, Reuter JS, Seetin MG, Mathews DH. RNAstructure: web servers for RNA secondary structure prediction and analysis. Nucleic Acids Research 2013, 41:W471-W474.

110. DeLano WL. The Pymol Molecular Graphics System. on World Wide Web http:/www.pymol.org 2002.

111. Asano K, Mizobuchi K. Copy number control of Incla plasmid Collb-P9 by competition between pseudoknot formation and antisense RNA binding at a specific RNA site. EMBO J. 1998, 17:5201-5213. 
112. Franch T, Gerdes K. U-turns and regulatory RNAs. Curr. Opin. Microbiol. 2000, 3:159-164.

113. Franch T, Petersen M, Wagner EGH, Jacobsen JP, Gerdes K. Antisense RNA regulation in prokaryotes: rapid RNA/RNA interaction facilitated by a general U-turn loop structure. J. Mol. Biol. 1999, 294:1115-1125.

114. Kim SW, Jeong IS, Jeong EJ, Tak J, Lee JH, Eo SK, Kang HY, Bahk JD. The terminal and internal hairpin loops of the ctRNA of plasmid pJB01 play critical roles in regulating copy number. Mol. Cells 2008, 26:26-33.

115. Riise E, Stoutgaard P, Bindslev B, K. N, Molin S. Molecular cloning and functional characterization of a copy number control gene (copB) of plasmid R1. J. Bacteriol. 1982, 151:1136-1145.

116. Ji Y, Marra A, Rosenberg M, Woodnutt G. Regulated antisense RNA eliminates alpha-toxin virulence in Staphylococcus aureus infection. J. Bacteriol. 1999, 181:6585-6590.

117. Chan WT, Balsa D, Espinosa M. One cannot rule them all: Are bacterial toxinsantitoxins druggable? FEMS Microbiol. Rev. 2015, 39:522-540.

118. Bai H, Luo X. Antisense antibacterials: from proof-of-concept to therapeutic perspectives, a search for antibacterial agents. 2012. Available at: http://www.intechopen.com/books/a-search-for-antibacterial-agents/antisenseantibacterials-from-proof-of-concept-to-therapeutic-perspectives.

119. Ray A, Nordén B. Peptide nucleic acid (PNA): its medical and biotechnical applications and promise for the future. FASEB J. 2000, 14:1041-1060.

120. Shen X, Corey DR. Chemistry, mechanism and clinical status of antisense oligonucleotides and duplex RNAs. Nucleic Acids Research 2018, 46:1584-1600.

121. Kumar CS, Dey D, Ghosh S, Banerjee M. Host membrane penetration and entry by nonenveloped viruses. Trends in Microbiology 2017.

122. Geller BL, Marshall-Batty K, Schnell FJ, McKnight MM, Iversen PL, Greenberg DE. Gene-silencing antisense oligomers inhibit Acinetobacter growth in vitro and in vivo. J. Infect. Dis. 2013, 208:1553-1560.

123. Kang S-M, Choi J-W, Lee Y, Hong S-H, Lee H-J. Identification of microRNA-Size, Small RNAs in Escherichia coli. Current Microbiology 2013, 67:609-613.

124. Nejman-Faleńczyk B, Bloch S, Licznerska K, Dydecka A, Felczykowska A, Topka G, Węgrzyn A, Węgrzyn G. A small, microRNA-size, ribonucleic acid regulating gene expression and development of Shiga toxin-converting bacteriophage $\Phi 24 \mathrm{~B}$. Scientific Reports 2015, 5:10080.

125. Choi J-W, Kwon T-Y, Hong S-H, Lee H-J. Isolation and characterization of a microRNA-size secretable small RNA in Streptococcus sanguinis. Cell Biochemistry and Biophysics 2018, 76:293-301.

126. Xu Y, Alvey RM, Byrne PO, Graham JE, Shen G, Bryant DA. Expression of genes in Cyanobacteria: adaptation of endogenous plasmids as platforms for high-level gene expression in Synechococcus sp. PCC 7002. In: Carpentier R, ed. Photosynthesis Research Protocols. Totowa, NJ: Humana Press; 2011, 273-293.

127. Gordon GC, Cameron JC, Pfleger BF. Distinct and redundant functions of three homologs of RNase III in the cyanobacterium Synechococcus sp. strain PCC 7002. Nucleic Acids Research 2018, 46:1984-1997.

128. Syvanen M. Evolutionary implications of horizontal gene transfer. Annu Rev Genet 2012, 46:341-358.

129. Ramos JL, Molina L, Segura A. Removal of organic toxic chemicals in the rhizosphere and phyllosphere of plants. Microbial Biotechnology 2009, 2:144-146.

130. Krell T, Lacal J, Guazzaroni ME, Busch A, Silva-Jiménez H, Fillet S, Reyes-Darías JA, Muñoz-Martínez F, Rico-Jiménez M, García-Fontana C, et al. Responses of Pseudomonas putida to toxic aromatic carbon sources. Journal of Biotechnology 2012, 160:25-32.

131. Tolmasky ME, Alonso JC. Plasmids: Biology and Impact in Biotechnology and Discovery: American Society of Microbiology; 2015. 


\section{Further readings}

We believe that there are, at least, two fundemental books to understand plasmid field:

1. Summers DK. The biology of plasmids, Oxford: Blackwell Science Ltd.; 1996.

2. Thomas CM. The horizontal gene pool, Amsterdam: Harwood Academic Publishers; 2000.

As recommended articles we suggest:

Brantl S. Antisense-RNA mediated control of plasmid replication - pIP501 revisited. Plasmid 2015, 78:4-16.

Chan WT, Balsa D, Espinosa M. One cannot rule them all: Are bacterial toxins-antitoxins druggable? FEMS Microbiol. Rev. 2015, 39:522-540.

Chattoraj D. Control of plasmid replication by iterons: no longer paradoxical. Mol. Microbiol. 2000, 37:467-476.

López-Villarejo J, Lobato-Márquez D, Díaz-Orejas R. Coupling between the basic replicon and the Kis-Kid maintenance system of plasmid R1: Modulation by Kis antitoxin levels and involvement in control of plasmid replication. Toxins 2015, 7:478-492.

Ramachandran R, Jha J, Paulsson J, Chattoraj D. Random versus cell cycle-regulated replication initiation in bacteria: Insights from studying Vibrio cholerae chromosome 2. Microbiol. Mol. Biol. Rev. 2017, 81.

Shen X, Corey DR. Chemistry, mechanism and clinical status of antisense oligonucleotides and duplex RNAs. Nucleic Acids Res. 2018, 46:1584-1600. 